\title{
Inpatient Medication Errors and Pharmacist Intervention at Ministry of Health Public Hospital, Riyadh, Saudi Arabia
}

\author{
Yousef Ahmed Alomi*, (iD) The Past Gen- \\ eral Manager of General Administration \\ of Pharmaceutical Care Head, National \\ Clinical Pharmacy and Pharmacy Practice \\ Head, Pharmacy R \& D Administration, \\ Ministry of Health, Riyadh 11392, SAUDI \\ ARABIA. \\ Nisreen Al-Shubaar, King Salman \\ Hospital, Ministry of Health, Riyadh 11392 \\ SAUDI ARABIA. \\ Nadia Lubad, King Salman Hospital, \\ Ministry of Health, Riyadh 11392, Riyadh, \\ SAUDI ARABIA \\ Fatimah Ali Albusalih, College of Clinical \\ Pharmacy, Imam Abdulrahman Bin Faisal \\ University (University of Dammam) Dam- \\ mam, SAUDI ARABIA.
}

\section{Correspondence:}

Dr. Yousef Ahmed Alomi, Bsc. Pharm, MSc. Clin Pharm, BCPS, BCNSP, DiBA The Past General Manager of General Administration of Pharmaceutical Care Head, National Clinical Pharmacy and Pharmacy Practice Head, Pharmacy R \& D Administration, Ministry of Health, Riyadh 11392, SAUDI ARABIA.

Phone no: +966504417712 E-mail:yalomi@gmail.com

Received: 20-10-2018;

Accepted: 19-12-2018

Copyright: (c) the author(s),publisher and licensee Pharmacology, Toxicology and Biomedical Reports. This is an open-access article distributed under the terms of the Creative Commons Attribution NonCommercial License, which permits unrestricted non-commercial use, distribution, and reproduction in any medium, provided the original work is properly cited.

This is an open access article distributed under the terms of the Creative Commons Attribution-NonCommercial-ShareAlike 4.0 License

Access this article online

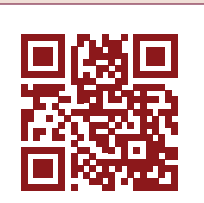

www.ptbreports.org

DOI:

10.5530/PTB.2019.5.8

\begin{abstract}
Objectives: To explore the inpatient medication errors and pharmacist intervention at Ministry of Health Hospital, Riyadh, Saudi Arabia. Methods: This is a 9-month cross-sectional study conducted at a 300-bed public hospital to evaluate pharmacist response and prevention of inpatient medication errors in adult and pediatric patients. There is a medication safety officer in the hospital along with a medication safety committee. The following information on medication errors were documented in the form available at the hospital: patient's demographic information, sources of medication errors, time of errors, type of errors, description of errors, causes of errors, recommendation to prevent such errors and the outcome of errors. The form was developed by using the National Coordinating Council (NCC) for Medication Error Reporting and Prevention (MERP) system. Results: According to the results, the pharmacist prevented a total of 3089 medication errors within 805 patients. About 3.8 errors per prescription were prevented. Most of the prevention occurred during prescribing stage (705 (99.2\%)). Patient-related errors $(1564(50.63 \%))$ and prescriber-related errors (1435 (46.46\%)) were the most type of prevented errors. Allergy was the most prevented subtype of errors $(560(91.4 \%))$ followed by patient's body weight $(543(88.6 \%))$ and prescriber data missing/unclear (347 (56.6\%)). Most of the errors that were prevented were near miss (93.3\%) followed by $6.3 \%$ of the errors that reached the patient but did not cause any harm. The highest percentage with respect to the causes of medication errors was missing clinical information (649 (83.7\%)) and miscommunication of drug order (627 (80.9\%)). The top 20 medications involved in medication errors were oral and intravenous injections (Paracetamol and enoxaparin injection, respectively). Conclusion: The pharmacist plays a very crucial role in preventing medication errors. In order to prevent medication errors and improve patient outcome, the pharmacist provides education to the healthcare professional about medication safety and establishes the intravenous medication guidelines.

Key words: Inpatient, Medication errors, Pharmacist, Intervention, Ministry of Health, Riyadh, Saudi
\end{abstract} Arabia.

\section{INTRODUCTION}

Clinical pharmacist plays a vital role in patient's care at hospitals. Nowadays, researchers are placing more emphasis on the relationship between the pharmacist and the patient. ${ }^{1}$ Training and experience of clinical pharmacists is considered unique because it is focused on therapeutics, as well as patient and provider providence of comprehensive drug management and by providers, we mean different healthcare professionals. ${ }^{1}$ Quality of life, economics, satisfaction of patient, appropriateness of medications, adverse reactions and events are the primary outcomes of the pharmacist intervention. ${ }^{1}$ MEs can be defined as incidents that occur in the medication processing regardless of the stage of origin and whether they cause harm to the patient. ${ }^{2}$ To be more specific, an ME is an occasion that can be prevented and may cause or prompt improper drug usage or harm patient regardless of the time of occurrence or when the drug was under the supervision of patient, consumer or healthcare professional. Such occasions might be identified with proficient practice, medicinal service items, techniques and frameworks, including compounding product labeling, dispensing, prescribing, monitoring order communication, administration, packaging, nomenclature, distribution and use. ${ }^{3}$ It is noteworthy that MEs should not be mistak- en for adverse drug reactions. ${ }^{4}$ An adverse drug reaction is defined as "an impact that is poisonous and unintended which happens at measurements utilized for prophylaxis, determination or therapy". Furthermore, prescribing errors are a notable issue in hospitals. Various studies have demonstrated that prescribing errors and adverse drug reactions are two of the fundamental causes of harmful incidents in hospital facilities. ${ }^{5-10}$ The improvement of prescribing practice is connected with the advancement of pharmacy practice in hospital. A further set of measures can be produced to give advantages outside the pharmacy. This may include writing care plans with possible interventions that can be provided to adjust the treatment for patients. Enhancement of medication safety, treatment efficacy and cost effectiveness is expected when using the recommended interventions in the care plan. ${ }^{11}$ Pharmacists' interventions were clinically estimated. ${ }^{12}$ Worldwide, several investigations have been conducted related to the pharmacist's intervention and prevention of MEs, ${ }^{13-21}$ whereas similar studies conducted locally in KSA are scarce. ${ }^{22}$ To the best of our knowledge, there are no studies conducted locally or in Gulf or in Middle Eastern countries regarding the pharmacist's role in preventing MEs in inpatient setting. Therefore, in this study, 
we aimed to explore the inpatient MEs and pharmacist's intervention at MOH public hospital, Riyadh, Saudi Arabia.

\section{METHODS}

This is a 9-month cross-sectional study conducted at a 300-bed public hospital through pharmacist response and prevention of inpatient MEs in adult and pediatric patients. The hospital has several specialties such as endocrinology, nephrology, cardiology, internal medicine, surgery, critical care, NICU, PICU, obstetrics and gynecology for adults and it also has pediatrics. The hospital had ambulatory care services and emergency services in addition to having accredited pharmaceutical services for inpatient, ambulatory care, total parenteral nutrition services, drug information services and computerized physician order entry system in both inpatient and outpatient units. In 2014, the Department of Pharmacy established Medication Safety Program. This program was founded in 2013 in Riyadh Region. It was a part of National Medication Safety Program of $\mathrm{MOH}$ and the Central Committee of Medication Committee is headed by the first author of this article. Riyadh Regional Medication Safety Committee is headed by the second author of this article. The Medication Safety Program is operated by part time pharmacist and the program consists of medication officer and local committee of medication safety. The officer monitors all MEs, adverse drug reactions and drug quality system inside the hospital by applying ISMP guidelines, ${ }^{23-26}$ Saudi Central Board of Health Care Accreditation standards ${ }^{27}$ and medication safety guidelines of the Joint Commission of Hospital Accreditation from the United States of America. ${ }^{28}$ In addition, the medication safety officer provides medication safety course to all healthcare professionals such as physicians, pharmacists and nurses and reports all medication safety-related issues to higher administration and to $\mathrm{MOH}$. The officer also documents drug events by using the MOH form of MEs. Any intervention should be documented in the ME form. The form collects information regarding patient, sources of MEs, qualification of the personnel who committed the error, time of error, suspected medications, drug classification, stage of medication orders, route of administration, type of MEs, description of errors, causes of errors, recommendation to prevent such errors and the outcome of MEs by using NCC for MERP system. ${ }^{29}$ The data are analyzed by using the Microsoft Excel Version 10.

\section{RESULTS}

The pharmacist prevented 3089 MEs occurred within 805 patients. About 3.8 MEs per prescription were prevented. The majority of patients involved in preventing MEs were in the age group of 18-65 years (71\%) (Table 1). Most of the interventions were provided as prescribing stage (705 (99.2\%)). Patient-related errors (1564 (50.63\%)) and prescriberrelated errors $(1435(46.46 \%))$ were the most prevented errors (Table $2 \mathrm{~A}$ and B). Allergy (560 (91.4\%)) was the most prevented subtype of error followed by patient's body weight $(543(88.6 \%))$ and prescriber data missing/unclear (347 (56.6\%)) (Table 3). Most of the errors prevented were near miss (93.3\%) followed by errors that reached the patient but did not cause any harm (6.3\%) (Table 4$)$. In packaging error, unit dose packaging (452 (77.1\%)) and syringe bottle packaging (42 (7.2\%)). Most route of administration MEs prevented were oral followed by intravenous and ophthalmic administration (Table 5A and B). The highest percentage of causes of MEs were clinical information missing (649 (83.7\%)) and miscommunication of drug order (627 (80.9\%)) (Table 6). The top 20 medications involved in MEs were oral and intravenous injections (paracetamol and enoxaparin injection, respectively) (Table 7).

\section{DISCUSSION}

Pharmacist interventions done in the several hospital and pharmacy units including the hospital outpatient clinics, inpatient departments
Table 1: Age of patients.

\begin{tabular}{|l|c|c|}
\hline \multicolumn{1}{|c|}{ Answer Options } & Response Count & Response Percent \\
\hline 30 Days & 8 & $1.8 \%$ \\
\hline 1 month - 6 years & 27 & $6.1 \%$ \\
\hline 6 - 12 years & 35 & $7.9 \%$ \\
\hline 12 -18 years & 27 & $6.1 \%$ \\
\hline $18-40$ years & 158 & $35.7 \%$ \\
\hline 40 - 65 years & 156 & $35.3 \%$ \\
\hline more than 65 years & 31 & $7.0 \%$ \\
\hline Answered Question & $\mathbf{4 4 2}$ & \\
\hline Skipped Question & $\mathbf{3 6 3}$ & \\
\hline
\end{tabular}

Table 2A: Pharmacist intervention of stage of medication operation.

\begin{tabular}{|l|c|c|}
\hline \multicolumn{1}{|c|}{ Answer Options } & Response Count & Response Percent \\
\hline Prescribing & 705 & $99.2 \%$ \\
\hline Preparing & 3 & $0.4 \%$ \\
\hline Dispensing & 2 & $0.3 \%$ \\
\hline Transcribing & 0 & $0.0 \%$ \\
\hline Administering & 1 & $0.1 \%$ \\
\hline Monitoring & 0 & $0.0 \%$ \\
\hline Answered Question & $\mathbf{7 1 1}$ & \\
\hline Skipped Question & $\mathbf{9 4}$ & \\
\hline
\end{tabular}

Table 2B: Type of medication errors preventions.

\begin{tabular}{|l|c|c|}
\hline \multicolumn{1}{|c|}{ Type of Error } & $\begin{array}{c}\text { Number of medication } \\
\text { errors }\end{array}$ & Percent \\
\hline Patient-Related error & 1564 & $50.63 \%$ \\
\hline Prescriber-Related errors & 1435 & $46.46 \%$ \\
\hline Drug-Related errors & 6 & $0.19 \%$ \\
\hline $\begin{array}{l}\text { Dosage form-Related } \\
\text { errors }\end{array}$ & 72 & $2.33 \%$ \\
\hline $\begin{array}{l}\text { Therapeutics-related } \\
\text { errors }\end{array}$ & 12 & $0.39 \%$ \\
\hline Total & $\mathbf{3 0 8 9}$ & $100.00 \%$ \\
\hline
\end{tabular}

and ambulance, as well as pharmacy preparation room, mixing intravenous solutions and during discharge. All pediatrics and adult patients as resources of the prevention of MEs. ${ }^{12-20,22,30-32}$ Our current site research mostly done at inpatient pharmacy with related preparation and adult patients. The majority of MEs prevented were in adult patient's setting, with less in pediatrics. Most of the errors occurred at prescribing stage, the pharmacist reporting of MEs more than physicians. As result, the pharmacist prevented MEs during preparation and dispensing stage this finding is similar to those reported by Scarsi et al. Khalili et al. Majid and Kuo et al. ${ }^{13,16-18}$ The majority of prevented errors were patient- and prescriber-related which shows that the hospital uses manual method of prescription rather than computerized system. Several mistakes related to the written allergy or patient body weight which not existed as well as or prescriber missing information. The hand writing of prescription and the high workload will lead to missing information. However, all 
Table 3: The subtype of medication errors preventions.

\begin{tabular}{|c|c|c|}
\hline Answer Options & $\begin{array}{c}\text { Response } \\
\text { Count }\end{array}$ & $\begin{array}{c}\text { Response } \\
\text { Percent }\end{array}$ \\
\hline \multicolumn{3}{|l|}{ Patient-Related error } \\
\hline Allergy not written & 560 & $91.4 \%$ \\
\hline Wrong Patient & 10 & $1.6 \%$ \\
\hline Patient Age not written & 269 & $43.9 \%$ \\
\hline Patient Body Wt. not written & 543 & $88.6 \%$ \\
\hline Diagnosis not written & 182 & $29.7 \%$ \\
\hline Non-existing patient & 0 & $0.0 \%$ \\
\hline \multicolumn{3}{|l|}{ Drug-Related errors } \\
\hline Drug dose Omission & 2 & $0.3 \%$ \\
\hline Drug incorrect Dose (under-dosing) & 2 & $0.3 \%$ \\
\hline Drug Incorrect Dose (overdosing) & 18 & $2.9 \%$ \\
\hline Wrong Drug & 5 & $0.8 \%$ \\
\hline Amount of drug missing/unclear/insufficient & 2 & $0.3 \%$ \\
\hline Drug Duration ( Inadequate) & 0 & $0.0 \%$ \\
\hline Drug Duration ( Excessive) & 3 & $0.5 \%$ \\
\hline Drug Dosing Frequency ( Excessive) & 31 & $5.1 \%$ \\
\hline Drug Dosing Frequency (Inadequate) & 3 & $0.5 \%$ \\
\hline \multicolumn{3}{|l|}{ Therapeutics-Related Errors } \\
\hline Drug Contraindications & 1 & $0.2 \%$ \\
\hline Drug-Drug Interaction & 5 & $0.8 \%$ \\
\hline Drug Diseases Interaction & 0 & $0.0 \%$ \\
\hline Infective Therapy & 3 & $0.5 \%$ \\
\hline Duplicate Therapy & 3 & $0.5 \%$ \\
\hline Dosage Form Related & 27 & $4.4 \%$ \\
\hline Drug Uncorrected/ unclear Formulation & 4 & $0.7 \%$ \\
\hline Drug Incorrect/ Unclear Route & 11 & $1.8 \%$ \\
\hline Drug Incorrect/Unclear Strength & 30 & $4.9 \%$ \\
\hline \multicolumn{3}{|l|}{ Prescriber-Related and general errors } \\
\hline Poor Handwriting & 69 & $11.3 \%$ \\
\hline Wrong Abbreviation & 34 & $5.5 \%$ \\
\hline Prescription date unclear & 322 & $52.5 \%$ \\
\hline No-Drug information on the prescription & 48 & $7.8 \%$ \\
\hline Prescriber data missing/ Unclear & 347 & $56.6 \%$ \\
\hline Department is missing / Unclear & 220 & $35.9 \%$ \\
\hline Prescriber sig. Missing/ Unclear & 341 & $55.6 \%$ \\
\hline Other (please specify) & 54 & \\
\hline Answered Question & 613 & \\
\hline Skipped Question & 192 & \\
\hline
\end{tabular}

Table 4: The outcome of medication error prevention.

\begin{tabular}{|c|c|c|c|}
\hline & & $\begin{array}{l}\text { Number of Medication } \\
\text { errors }\end{array}$ & Percent \\
\hline \multirow{11}{*}{ 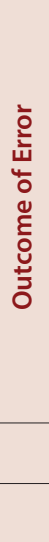 } & A (Potential Risk) & 0 & $0.0 \%$ \\
\hline & B (Near miss) & 713 & $93.3 \%$ \\
\hline & $\mathrm{C}$ & 48 & $6.3 \%$ \\
\hline & $\mathrm{D}$ & 3 & $0.4 \%$ \\
\hline & E & 0 & $0.0 \%$ \\
\hline & $\mathrm{F}$ & 0 & $0.0 \%$ \\
\hline & G (SE) & 0 & $0.0 \%$ \\
\hline & $\mathrm{H}(\mathrm{SE})$ & 0 & $0.0 \%$ \\
\hline & I (SE) & 0 & $0.0 \%$ \\
\hline & Answered question & 764 & $100.0 \%$ \\
\hline & Skipped question & 41 & \\
\hline
\end{tabular}

Table 5A: The type of medication packaging.

\begin{tabular}{|l|c|c|}
\hline \multicolumn{1}{|c|}{ Answer Options } & $\begin{array}{c}\text { Response } \\
\text { Count }\end{array}$ & Response Percent \\
\hline Unit Dose & 452 & $77.1 \%$ \\
\hline Syringe & 20 & $3.4 \%$ \\
\hline Bottle & 42 & $7.2 \%$ \\
\hline Single Dose Vial/ Ampoule & 30 & $5.1 \%$ \\
\hline Multi-Dose Vial & 12 & $2.0 \%$ \\
\hline IV Piggy Bag & 0 & $0.0 \%$ \\
\hline Intravenous Solution & 30 & $5.1 \%$ \\
\hline Other (please specify) & 0 & $0.0 \%$ \\
\hline Answered question & $\mathbf{5 8 6}$ & \\
\hline Skipped question & $\mathbf{2 1 9}$ & \\
\hline
\end{tabular}

Table 5B: Route of administration medication errors.

\begin{tabular}{|l|c|c|}
\hline \multicolumn{1}{|c|}{ Answer Options } & Response Count & Response Percent \\
\hline Oral & 533 & $76.8 \%$ \\
\hline Eye & 23 & $3.3 \%$ \\
\hline Ear & 1 & $0.1 \%$ \\
\hline Nose & 3 & $0.4 \%$ \\
\hline Inhalation & 1 & $0.1 \%$ \\
\hline IV & 105 & $15.1 \%$ \\
\hline IM & 1 & $0.1 \%$ \\
\hline IT & 0 & $0.0 \%$ \\
\hline SC & 4 & $0.6 \%$ \\
\hline Topical Skin & 19 & $2.7 \%$ \\
\hline Rectal & 1 & $0.1 \%$ \\
\hline Nasogastric Tube (NGT) & 3 & $0.4 \%$ \\
\hline Answered Question & $\mathbf{6 9 4}$ & \\
\hline Skipped Question & $\mathbf{1 1 1}$ & \\
\hline
\end{tabular}


Table 6: Causes of medication errors.

\begin{tabular}{|c|c|c|}
\hline & $\begin{array}{l}\text { Response } \\
\text { Count }\end{array}$ & $\begin{array}{c}\text { Response } \\
\text { Percent }\end{array}$ \\
\hline Clinical information missing & 649 & $83.7 \%$ \\
\hline Drug information missing & 7 & $0.9 \%$ \\
\hline Miscommunication of drug order & 627 & $80.9 \%$ \\
\hline Drug name, label, package problem & 6 & $0.8 \%$ \\
\hline Drug storage or delivery problem & 2 & $0.3 \%$ \\
\hline Drug delivery device problem & 1 & $0.1 \%$ \\
\hline $\begin{array}{l}\text { Environmental, staffing or workflow } \\
\text { problem }\end{array}$ & 1 & $0.1 \%$ \\
\hline Lack of staff education & 1 & $0.1 \%$ \\
\hline Patient education problem & 0 & $0.0 \%$ \\
\hline $\begin{array}{l}\text { Lack of quality control or independent } \\
\text { check system }\end{array}$ & 6 & $0.8 \%$ \\
\hline Answered Question & 775 & \\
\hline Skipped Question & 30 & \\
\hline
\end{tabular}

Table 7: Top 20 medications involved prevention of errors.

\begin{tabular}{|c|l|c|}
\hline$\#$ & \multicolumn{1}{|c|}{ Medication } & Number Of Errors \\
\hline 1 & Paracetamol oral & 29 \\
\hline 2 & Paracetamol IV & 17 \\
\hline 3 & Enoxaparin injection & 14 \\
\hline 4 & Amoxicllin/Clavulanic Acid oral & 14 \\
\hline 5 & Omeprazole IV & 13 \\
\hline 6 & Metronidazole oral & 12 \\
\hline 7 & Alfacalcidol injection & 11 \\
\hline 8 & Ciprofloxacin Oral & 11 \\
\hline 9 & Omeprazole oral & 9 \\
\hline 10 & Cefuroxime 750mg & 6 \\
\hline 11 & Erythropoietin injection & 6 \\
\hline 12 & Ibuprofen oral & 6 \\
\hline 13 & Multivitamin oral & 4 \\
\hline 14 & Amoxicillin oral & 4 \\
\hline 15 & Clarithromycin oral & 4 \\
\hline 16 & Lactulose oral & 4 \\
\hline 17 & Ondansetron oral & 4 \\
\hline 18 & Alfacalcidol oral & 4 \\
\hline 19 & Cholecalciferol oral & 3 \\
\hline 20 & Antirabies injection & \\
\hline
\end{tabular}

basic information related to patient or prescriber was well documented with computerized physician order entry. This finding shows that most of the errors prevented were near miss and did not reach the patient; this reflects a good effort on the part of pharmacy team at inpatient pharmacy. Similar results have been reported by Kuo et al. the highest percentages of type errors with different level severity. ${ }^{18}$ There was no cases where the patient was harmed or died. In this study, most of the mistakes occurred at unit dose system and intravenous preparations in the inpatient pharmacy. In case of the unit dose system, there may not be double-checking performed and the pharmacy had intravenous admixture system during the study period. The majority of errors were missing clinical information or miscommunication with healthcare staff, which might be due to manual prescribing system. Most of the medications that were implicated in prevention of drug errors were Paracetamol or intravenous enoxaparin. This may be because it is a parental preparation and the pharmacy does not have intravenous preparation unit. This finding is similar to those reported by Khalili et al. who conducted a study on inpatient setting, whereas our findings were contradictory to those reported by Kuo et al. and Poudel et al. this might be because their research site was conducted in both outpatient plus inpatient setting or outpatient alone. ${ }^{16-19}$ In addition, the high-risk medication procedures may not be existing in their hospital. This study shows the high impact of medications safety program at public hospital, which is very critical to expand the program to cover all hospital units and implement the program at all $\mathrm{MOH}$ hospitals in KSA.

\section{CONCLUSION}

The pharmacist plays an essential role in preventing MEs through medication safety program at inpatient setting. Targeting to educate healthcare providers about medication safety is highly recommended. The role of pharmacist should expand to cover all healthcare services at $\mathrm{MOH}$ hospitals in KSA.

\section{ACKNOWLEDGEMENT}

None.

\section{CONFLICT OF INTEREST}

None.

\section{ABBREVIATIONS}

MEs: Medication errors; UK: United Kingdom; MOH: Ministry of Health; NICU: Neonatal Intensive Care Units; PICU: Pediatrics Intensive Care Units; ISMP: Institute of Safe Medication Practice; NCC: National Coordinating Council; MERP: Medication Error Reporting and Prevention; KSA: Kingdom of Saudi Arabia.

\section{ORCID ID}

Yousef Ahmed Alomi (iD https://orcid.org/0000-0003-1381-628X

\section{REFERENCES}

1. Kaboli PJ, Hoth AB, McClimon BJ, Schnipper JL. Clinical pharmacists and inpatient medical care: A systematic review. Archives of Internal Medicine. 2006;(9):955-64

2. Williamson S. Reporting medication errors and near misses. Medication Safety: An Essential Guide. Cambridge University Press. 2009;155-72.

3. NCC MERP. About Medication Errors [Internet]. [cited 2018 Oct 31]. Available from: https://www.nccmerp.org/about-medication-errors

4. Word Health Organization. Safety of medicines: A guide to detecting and reporting adverse drug reactions. WHO Publ [Internet]. 2002. [cited 2018 Oct 31]; Available from: http://apps.who.int/medicinedocs/en/d/Jh2992e/

5. Bates DW, Cullen DJ, Laird N, Petersen LA, Small SD, Servi D, et al. Incidence of adverse drug events and potential adverse drug events. Implications for prevention. ADE Prevention Study Group. JAMA. 1995;274(1):29-34.

6. Lisby M, Nielsen LP, Mainz J. Errors in the medication process: frequency, type and potential clinical consequences. Int J Qual Heal Care. 2005;17(1):15-22.

7. Thomas EJ, Studdert DM, Burstin HR, Orav EJ, Zeena T, Williams EJ, et al. Incidence and types of adverse events and negligent care in Utah and Colorado. Med Care. 2000;38(3):261-71

8. Brennan TA, Leape LL, Laird NM, Hebert L, Localio AR, Lawthers AG, et al. Incidence of adverse events and negligence in hospitalized patients: results of the Harvard Medical Practice Study I. Qual Saf Health Care. 2004;13(2):145-51.

9. Leape LL, Brennan TA, Laird N, Lawthers AG, Localio AR, Barnes BA, et al. The nature of adverse events in hospitalized patients. Results of the Harvard Medi- 
cal Practice Study II. N Engl J Med. 1991;324(6):377-84.

10. Kaushal R, Bates DW, Landrigan C, McKenna KJ, Clapp MD, Federico F, et al. Medication Errors and Adverse Drug Events in Pediatric Inpatients. JAMA. $2001 ; 285(16): 2114-20$.

11. Avedis D. Evaluating the Quality of Medical Care. Milbank Q. 2005;83(4):691729.

12. Buurma H, Smet PAGMD, Leufkens HGM, Egberts ACG. Evaluation of the clinical value of pharmacists' modifications of prescription errors Henk. Br J Clin Pharmacol. 2004;58(5):503-11.

13. Scarsi KK, Fotis MA, Noskin GA. Pharmacist participation in medical rounds reduces medication errors. Am J Heal Pharm. 2002;59(21):2089-92.

14. Grissinger MC, Globus NJ. The Role of Managed Care Pharmacy in Reducing Medication Errors. J Manag Car Pharm. 2003;9(1):62-5.

15. Knudsen $P$, Herborg $H$, Mortensen AR, Knudsen M, Hellebek A. Preventing medication errors in community pharmacy: frequency and seriousness of medication errors. Qual Saf Heal Care. 2007;16(4):291-6.

16. Khalili H, Farsaei S, Rezaee H, Dashti-Khavidaki S. Role of clinical pharmacists interventions in detection and prevention of medication errors in a medical ward. Int J Clin Pharm. 2011;33(2):281-4.

17. Majid AK. The Roles of Clinical Pharmacy in Reducing Medication Errors. In Res J Pharm. 2012;3(9):76-83

18. Kuo GR, Touchette DR, Marinac JS. Drug Errors and Related Interventions Reported by. Pharmacotherapy. 2013;33(3):253-65.

19. Poudel RS, Piryani RM, Shrestha S, Prajapati A, Adhikari B. Prescription errors and pharmacist intervention at outpatient pharmacy of Chitwan Medical College. J Chitwan Med Coll. 2015;5(2):20.

20. Tong EY, Roman CP, Mitra B, Yip GS, Gibbs H, Newnham HH, et al. Reducing medication errors in hospital discharge summaries: A randomised controlled trial. Med J Aust. 2017;206(1):36-9.

21. Wheeler AJ, Scahill S, Hopcroft D, Stapleton H. Reducing medication errors at transitions of care is everyone's business. Aust Prescr. 2018;41(3):73-7.

22. Al-Dhawailie AA. Inpatient prescribing errors and pharmacist intervention at a teaching hospital in Saudi Arabia. Saudi Pharm J. 2011;19(3):193-6.

23. Institute for Safe Medication Practices. 2011 ISMP Medication Safety Self-Assessment for Hospitals. 2011

24. Alex JA, Ronna BH, Coleen KE. ISMP Medication Safety Self-assessment $₫$ for Community/Ambulatory Pharmacy. 2017.

25. Assessment S. ISMP International Medication Safety Self-assessment $₫$ for Oncology. 2012

26. Jean C, Wiliam D, Michael E, Michael G, Russel JWM. ISMP Medication Safety Self-assessment for Antithrombotic Therapy. 2017.

27. Medication Management (MM). In: National Hospital Standards. $2^{\text {nd }}$ Editio. Saudi Central Board for Accreditation of Healthcare Institutions. 2015;194-211.

28. The Joint Commission. Comprehensive Accreditation Manuals. Joint Commission Resources. 2016

29. Hartwig SC, Denger SD, Schneider PJ. Severity-indexed, incident report-based medication error-reporting program. Am J Hosp Pharm. 1991;48(12):2611-6.

30. Al Rahbi HAM, Al-Sabri RM, Chitme HR. Interventions by pharmacists in outpatient pharmaceutical care. Saudi Pharm J. 2014;22(2):101-6.

31. Cunningham KJ. Analysis of Clinical Interventions and the Impact of Pediatric Pharmacists on Medication Error Prevention in a Teaching Hospital. J Pediatr Pharmacol Ther. 2012;17(4):365-73.

32. Kripalani S, Roumie CL, Dalal AK, Cawthon C, Businger A, Eden SK, et al. Effect of a Pharmacist Intervention on Clinically Important Medication Errors after Hospital Discharge: A Randomized Controlled Trial. Ann Intern Med. 2013;157(1):1-10. 